\title{
THREE DIMENSIONAL SURFACE REPRESENTATION OF KNEE AND HIP JOINT TORQUE CAPABILITY
}

\author{
K.A. Khalaf, M. Parnianpour ${ }^{\star}$, T. Karakostas ${ }^{\star}$
}

Department of Biomedical Engineering, The University of Miami, Florida

*Department of Biomedical Engineering, The Ohio State University, Ohio, U.S.A.

\section{ABSTRACT}

The need to develop objective functional muscle torque capability models has been a major concern for exercise scientists, rehabilitation therapists, as well as biomechanists and ergonomists, for many decades. This study provides a surface response normative database of 3-D dynamic torque capability profiles for the lower extremity knee and hip joints for twenty normal males and females. The results of the regression analyses were presented for each subject per direction of exertion for each joint depicting a wide range of adjusted $R^{2}$ values for each of the two joints (knee flexion: .26-.91, knee extension: .23-.80; hip flexion: .33-81, hip extension: .31-.80). Furthermore, the results showed that joint torque capability was significantly influenced by dynamic parameters such as the angular velocity, and that the interaction between angular position and velocity was highly significant. Such 3-D representation may be used as a "performance capacity envelope" to comprehensively characterize an individual's dynamic joint torque capability. Potential applications cover a broad spectrum ranging from rehabilitation to ergonomic and biomechanical applications and have significant implications in terms of guiding job assignment, return to work, as well as prognosis during the rehabilitation processes.

Biomed Eng Appl Basis Comm, 2001 (April); 13: 53-65.

Keywords: Performance capacity, Regression, Rehabilitation, Ergonomics, Multidimensional torque capacity profiles.

\section{INTRODUCTION}

The accurate assessment of functional muscular torque capability (maximum torque generation capability of a muscle group performing physiological work in a particular functional posture/movement) has been the objective of exercise scientists, rehabilitation therapists, as well as biomechanists and ergonomists, for many decades. Whether the objectives are to determine

Received: Feb. 21, 2001; accepted: March 30, 2001.

Correspondence: Kinda Khalaf, Ph.D.

Dept. of Biomedical Engineering

The University of Miami

1251 Memorial Dr., MCA 219A

Coral Gables, Florida 33146, U.S.A.

E-mail: kkhalaf@miami.edu the extent of disability, to compare the effects of various conditioning programs, to document the benefits of a specific therapeutic exercise, or to prevent manual material handling (MMH) injuries by allowing appropriate task assignment based on a worker's torque capability, the common denominator is the need for objective and reliable means of quantifying functional muscular performance.

From an ergonomic point of view, quantitative assessment of the feasibility of task performance is an intricate process which combines the multidimensional task demand profile with an individual's multidimensional performance capacity profile [1]. For many years, ergonomists and rehabilitation engineers have studied the relationships between physical capacity and job requirements for the purpose of minimizing the mismatch between the two [2]. A review of litera- 
the mismatch between the two [2]. A review of literature shows an abundance of torque capability assessment studies on the isolated single joint exertions level [3-5], as well as the coordinated multijoint level [6-11]. Furthermore, with the advent of isokinetic exercise about three decades ago, and the realization that dynamic testing of muscle function is necessary for the objective evaluation of most human movements, isokinetic testing protocols have been extensively used for musculoskeletal performance assessment $[4,9,12-15]$.

While considerable research has been devoted to torque capability prediction models on the joint level, the void still exists for a method which comprehensively satisfies the needs of the wide spectrum of potential users $[4,15,16]$. The majority of existing dynamic models and normative databases are reported in the form of torque as a function of joint angle $[4,14,17]$. Such models have been related to the variations of the muscle moment arm as a function of joint angles, and the length-tension relationships, well documented by physiological studies of muscle mechanics [18-21]. In reality, joint torque capability is a function of both the joint angular position and angular velocity since the moment of a force that a muscle group generates about a joint depends not only on the relative lengths of the contributing muscles, but also on the rate with which the muscle length changes $[16,22]$. Descriptive models of joint torque capability should take this interaction into consideration for more accurate quantitative characterization of musculoskeletal performance $[16,23]$.

Therefore, the main objective of this study is to develop a normative database of 3-D dynamic surface responses of joint flexion and extension torque capability for the lower extremity knee and hip joints. In addition, the effects of the joint angular position, joint angular velocity, direction of exertion, and gender on the torque capability will be investigated. The underlying intent is to provide ergonomists, clinicians, and practitioners with a better tool for predicting joint torque capability as compared to the traditional use of a single value representation without consideration of the inherent tension-length-velocity relationship for contractile machinery and the dynamic change of the muscles' moment arms as a function of angular position. The resulting profiles can be combined with task demand parameters in order to provide appropriate task assignment based on an individual's torque capability [24]. Such data representation could be of further use in quantitative gait studies to validate the muscle moments estimated by the various modeling approaches $[20,21]$, and in the formulation of biomechanical simulation models $[23,25]$. The accuracy of predictions of the upper limit of performance in simulation models is highly dependent on the validity of the imposed constraints. The lower-extremity torque capability regressions developed in this study would pro- vide dynamic torque capability limits that could be used as functional constraints in the simulation of physical activities such as lifting $[23,25]$, or gait [26].

\section{MATERIALS AND METHODS}

\section{Subjects}

Twenty healthy males and females participated in this study. The mean (s.d.) age, mass, and stature were $26.2(3.8)$ years, $85.1(14.0) \mathrm{kg}$, and $178.6(10.7) \mathrm{cm}$ for the males $(\mathrm{N}=10)$, and $24.2(2.6)$ years, $58.3(7.2)$ $\mathrm{kg}$, and $165.3(8.4) \mathrm{cm}$ for the females $(\mathrm{N}=10)$ respectively. None of the subjects reported a history of musculoskeletal disorders or pain in the previous year. The subjects were briefed on the study's goals and procedures prior to signing an informed consent form approved by the human subjects committee.

\section{Apparatus}

The dynamic joint torque capability of the subjects was studied for the knee and hip joints using the KIN_COM 125E Plus muscle testing and training system from Chattecx. Corp. (Chattanooga, TN) [27]. The KIN COM is a closed loop system, which consists of a servomotor-controlled rotary arm equipped with an attached user-positioned load cell. A joint-specific attachment comfortably fastens the subject's limb to the load cell such that the joint axis is aligned with the axis of the dynamometer. The load cell measures the reaction forces between the limb and rotary arm in the direction of joint motion. The torque about each joint is obtained by multiplying the force by the linear distance between the joint axis and the load cell. Prior to the onset of the experiment, the angle, velocity, and force calibration procedures were performed as suggested by the manufacturer (KIN_COM 125E Plus Clinical Desk Reference, Chattecx Corp.) [27]. In addition, the force calibration was verified at various points throughout the experiment by placing known weights on the lever arm. The coefficient of determination $\left(R^{2}\right)$ between the recorded and actual measurements was in the range of .97 to .99 . The interclass correlation coefficient (ICC) for reliability of measured force between days was 0.99 . Good reliability results have been reported for the KIN-COM when testretest analyses were performed with inert weights [28]. The ICC for reliability of measured force between days for forces ranging from 22 to 450 Newtons was 0.99 . The $R^{2}$ between recorded and actual measurements has also been reported as .99 [28].

\section{Experimental Design}

The independent variables in this study consisted of joint angular position; joint angular velocity, direction of exertion (flexion/extension), and gender for the 

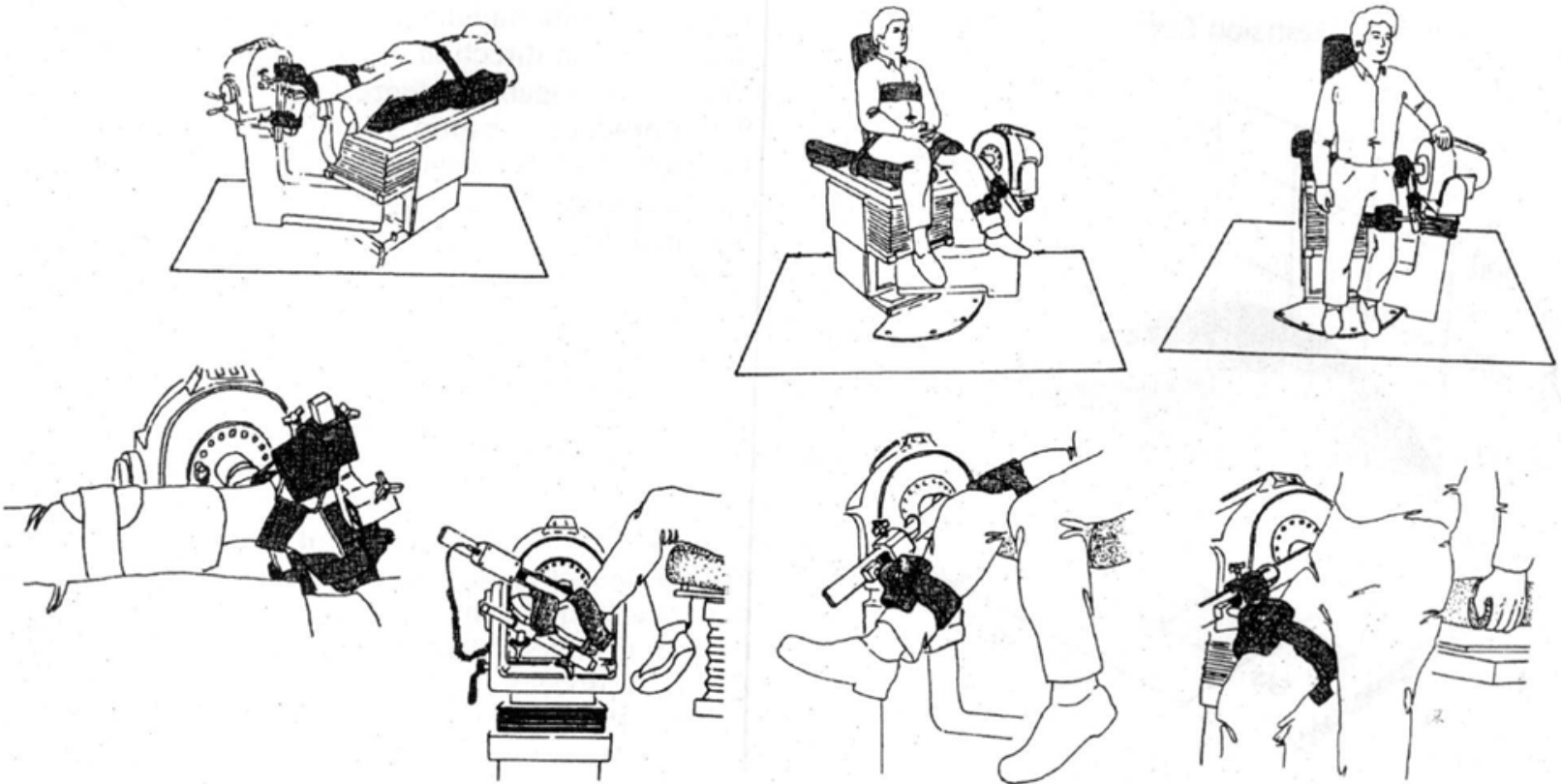

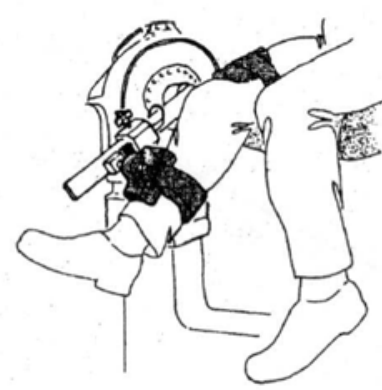

(1b)

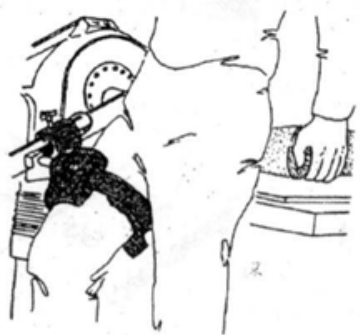

(1c)

(1a)

\begin{tabular}{|c|c|c|}
\hline Joint & Angular Position (Deg) & Angular Velocity(Deg/sec) \\
\hline $\begin{array}{c}\text { Knee } \\
\text { (0 deg full extension) }\end{array}$ & $\mathbf{0 , 2 0 , 4 0 , 6 0 , 8 0}$ & $10,50,100,150,200,250$ \\
\hline $\begin{array}{c}\text { Hip* } \\
\text { (0 deg full extension) }\end{array}$ & $\mathbf{0 , 1 5 , 3 0 , 4 5 , 6 0}$ & $10,50,100,150,200,250$ \\
\hline
\end{tabular}

Hip*: 0 degrees full extension (instructed to keep the knee at a slightly flexed comfortab

Fig. 1. Test configurations for the ankle joint (1a), knee joint (1b), and hip joint (1c) using the KINCOM 125E Plus dynamometer and attachments.

two joints studied (knee and hip). The measured joint torque capability $(\mathrm{Nm})$ was the only defined dependent variable. Figure $1(\mathrm{a}, \mathrm{b})$ illustrates the joint-specific test configurations corresponding to the tested joints as recommended by the KIN-COM user guide [27]. The Figure also includes the joint-specific angular positions and velocities used during the isokinetic testing protocol.

\section{Experimental Protocol}

The isokinetic test protocol was designed such that the subjects began with two submaximal and one maximal practice/warm-up trials at each velocity over the full range of motion. Using a custom-programmed isokinetic protocol, the maximal voluntary joint concentric flexor and extensor joint torque capability were measured for the three joints at the predefined levels of angular velocity through the joint-specific ranges of motion (Figure 1). Two sets of two flexion/extension repetitions were collected at each velocity. Verbal instructions were given to encourage maximal performance during each test. In addition, during the testing of the hip joint, the subjects were instructed to keep the knee in a slightly flexed comfortable position. The subjects rested for at least 60 seconds between sets, and 2 minutes between velocitics to minimize the effects of muscular fatigue. The selection criterion for the velocity range was based on literature values representing a reasonable proportion of task demands placed on speed during everyday life [13-15], as well as the results of the coordinated lifts performed in our previous study [11].

The joint torque capability tests of the two joints were performed during separate sessions for each subject in order to minimize fatigue effects. Furthermore, the velocities were administered in a systematically counterbalanced order and the trials were randomized to minimize unintended fatigue and order effects. The KIN_COM dynamometer imposed a limit of a 250 degrees/sec on the maximum velocity for safety purposes. The angular position, velocity, and force were sampled at $100 \mathrm{~Hz}$ and saved on a personal computer for postprocessing.

\section{Analysis}

To ensure that the non-isokinetic portion of the 


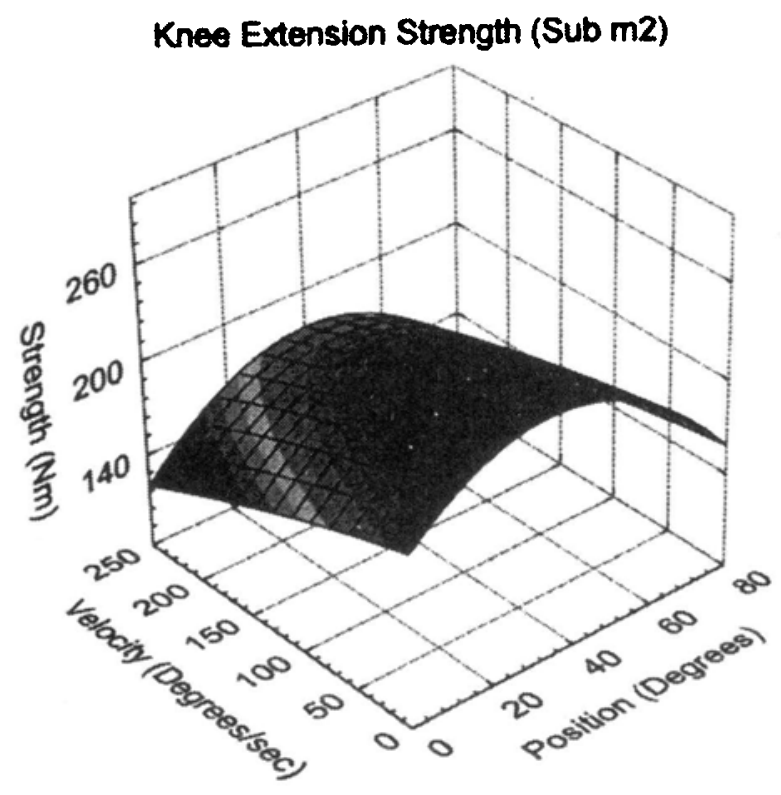

Fig. 2. Knee extension torque capability as a function of angular position and velocity (Sub $\mathrm{m} 2$ ).

exertions was not included in the analysis, torque values within a bandwidth of \pm 3 degrees for the target angular positions (joint-specific angular positions, Table 1) and $\pm 10 \%$ for the target angular velocities (joint-specific angular velocities, Table 1) were averaged to estimate each subject's maximum joint torque capability $(\mathrm{Nm})$ as a function of both angular position and velocity. The measured torques were corrected for the effects of gravity using the subjects' anthropometric data [22].

Based on the results of preliminary statistical analyses performed on simulated knee joint torque capability data using the interactive graphics-based software SIMM (Software for Interactive Musculoskeletal Modeling, MusculoGraphics Inc., Evanston, IL.), a second order multiple regression model was performed on the measured data resulting in equations of the dynamic joint torque capability as a function of angular position and velocity in flexion and extension for each joint. The adequacy of a second order model is presented in the Appendix. The second order linear multiple regression model was of the general form:

$S(\theta, \dot{\theta})=\beta_{0}+\beta_{1} \theta+\beta_{2} \dot{\theta}+\beta_{3} \theta^{2}+\beta_{4} \dot{\theta}^{2}+\beta_{5} \theta \dot{\theta}+\varepsilon$

Where $\mathrm{S}(\theta, \dot{\theta})$ : Joint torque capability $(\mathrm{Nm})$ as a function of joint angular position (Deg) and velocity (Deg/sec). $\beta_{0}-\beta_{5}$ : Regression coefficients $\left(\beta_{0}\right.$ : intercept). $\varepsilon$ : Uncorrelated normally distributed random error; $\varepsilon \sim N\left(0, \sigma^{2}\right)$.

When using the above joint torque capability regression model for constructing the joint torque capability profiles, it is necessary to input the absolute val- ues of the joint angular positions since the model was developed per direction of exertion (flexion/extension). The torque capability regression equations were plotted to produce dynamic 3-D torque capability surfaces for each of the subjects per direction. For convenience, the torque capability regression equations were also obtained for the males, females, and the combined male/female population. Subjects $\mathrm{m} 1-\mathrm{m} 10$ correspond to the male population, while subjects f11-f20 represent the females. The results of the reported regression analyses consist of the estimated coefficients $\left(B_{0}-B_{5}\right)$, adjusted $R^{2}$ values, the model's overall significance level ( $\mathrm{p}$ values), as well as the standard error of regression. A repeated measures analysis of variance (ANOVA) was used to test for the effects of gender, angular position, angular velocity, and direction on the dynamic torque capability of each joint. Furthermore, the various interaction effects were evaluated using the ANOVA procedure. A post-hoc Tukey test was used to identify the levels of the dependent variables leading to torque capability values which differed significantly.

The robustness of the regression models for each subject may be investigated statistically by using the models to predict the torque capability of the subset trials (since two sets of two flexion/extension repetitions were collected at each velocity). As an cxample, using the data from each trial of a typical male subject $(\mathrm{m} 3)$, the robustness of the regression model was evaluated by examining the performance of three different cases for each joint: (a) the regression model resulting from joint data of trial 1, (b) the regression model resulting from joint torque capability averaged data (trial 1 and 2), and (c) regression models developed from trial 1 data were applied to fit trial 2 data.

\section{RESULTS}

The high inter-subject variability resulted in relatively low predictive regression models for the torque capability surface responses based on the whole population data. The results of the regression analysis are tabulated for each subject per direction of exertion for each joint (Tables 1-4). In addition, these tables also include the regression results for the males, females, and combined population. Examination of Tables 1-4 depict a wide range of adjusted $R^{2}$ values for each of the joints (knee flexion: .26-.91, knee extension: .23.80 ; hip flexion: $.33-81$, hip extension: $.31-80$ ). This reflects the adequacy of the second order regressicn model for some but not all individuals. The standard errors of regression $(\mathrm{Nm})$ corresponding to each of the models, are also variable (Tables 1-4): knee: 3.8330.23, hip: 4.61-14.91. As expected, the regression results based on the populations (males, females, and combined) show much lower adjusted $R^{2}$ and higher standard error of regression values (Tables 1-4). 
Table 1. Regression summary for the knee fiexion torque capability for 20 subjects (N=m1-m10: males, f11-f20: females), and for the male, female and whole population , $B_{0}-B_{5}$ : regression model coefícients, $R_{n}{ }^{2}$ : adjusted $R^{2}, P$ : $P$ value, SE: standard error of regression ( $\mathrm{Nm})$.

\begin{tabular}{|c|c|c|c|c|c|c|c|c|c|}
\hline Sub & $\mathbf{B}_{\mathbf{0}}$ & $\mathbf{B}_{1}$ & $B_{2}$ & $\mathbf{B}_{3}$ & $B_{4}$ & $\mathbf{B}_{5}$ & $P$ & $R_{n}^{2}$ & SE \\
\hline m1 & 142.40 & 1.0953 & -.0380 & -.0125 & -.0003 & -.0010 & .00023 & .53 & 13.88 \\
\hline $\mathrm{m} 2$ & 139.36 & 1.4882 & -.1950 & .0184 & .0005 & .0003 & .00013 & .55 & 11.68 \\
\hline $\mathrm{m} 3$ & 154.86 & 1.0541 & .0498 & -.0129 & -.0007 & -.0005 & .00001 & .75 & 8.94 \\
\hline $\mathrm{m4}$ & 151.47 & 5.7538 & .8389 & -.0660 & .0027 & -.0051 & .00378 & .39 & 15.24 \\
\hline $\mathrm{m5}$ & 120.77 & .7469 & .1129 & -.0078 & -.0003 & -.0007 & .00035 & .51 & 5.41 \\
\hline $\mathrm{m} 6$ & 94.61 & .55604 & .0748 & -.00275 & -.00010 & -00123 & .0122 & .32 & 7.82 \\
\hline $\mathrm{m7}$ & 117.37 & .996 & .1222 & -.0094 & -.0003 & -.0011 & .00265 & .41 & 8.2857 \\
\hline $\mathrm{m} 8$ & 120.38 & .7256 & .0133 & -.0061 & -.0001 & -.0005 & .0111 & .44 & 8.431 \\
\hline $\mathrm{m} 9$ & 103.01 & .3123 & .0920 & -.0045 & -.0003 & -.0007 & .00166 & .44 & 6.02 \\
\hline $\mathbf{m 1 0}$ & 109.38 & .3638 & -.0665 & -.0047 & .0003 & -.0004 & .0283 & .26 & 6.0956 \\
\hline $\begin{array}{c}\text { mean } \\
(\mathrm{sd})\end{array}$ & & & & & & & & $\begin{array}{l}.46 \\
(.13)\end{array}$ & $\begin{array}{c}9.10 \\
(3.19)\end{array}$ \\
\hline$t 11$ & 86.16 & .5798 & .3460 & -.0070 & .0013 & -.0015 & .00000 & .71 & 7.53 \\
\hline 112 & 86.25 & .3475 & .1415 & -.0049 & -.0005 & -.0007 & .00025 & .53 & 5.91 \\
\hline 113 & 90.74 & .0083 & .0986 & .00289 & -.0001 & -.0022 & .0065 & .33 & 6.06 \\
\hline $\mathrm{H14}$ & 100.13 & .2683 & .0647 & -.0021 & .0002 & -.0003 & .0094 & .65 & 5.27 \\
\hline $\mathrm{f15}$ & 103.50 & .1218 & .0360 & -.0033 & -.0002 & .0006 & .0467 & .60 & 6.66 \\
\hline 116 & 103.77 & .0569 & .0562 & -.0025 & -.0003 & -.0001 & .0432 & .33 & 12.72 \\
\hline $\mathrm{H7}$ & 126.06 & .1815 & -.0184 & -.0050 & -.0002 & .0005 & .0001 & .58 & 6.28 \\
\hline 18 & 115.02 & .3709 & .0866 & -.0041 & -.0003 & -.0007 & .0000 & .91 & 3.83 \\
\hline H9 & 109.41 & .3048 & .3048 & -.0059 & .0003 & .0002 & .0003 & .52 & 6.97 \\
\hline 120 & 126.61 & .1443 & -.2435 & -.0045 & .0005 & .0012 & .0018 & .43 & 8.44 \\
\hline $\begin{array}{l}\text { mean } \\
\text { (s.d.) }\end{array}$ & & & & & & & & $\begin{array}{r}.56 \\
(.17) \\
\end{array}$ & $\begin{array}{r}6.97 \\
(2.25)\end{array}$ \\
\hline $\begin{array}{l}\text { Males } \\
\text { (s.d) }\end{array}$ & $\begin{array}{l}120.87 \\
(a .13)\end{array}$ & $\begin{array}{l}.757 \\
(15)\end{array}$ & $\begin{array}{l}.0058 \\
1.05\end{array}$ & $\begin{array}{l}-0002 \\
(0016)\end{array}$ & $\begin{array}{l}-0001 \\
(0000)\end{array}$ & $\begin{array}{r}00007 \\
(0005)\end{array}$ & .0001 & .30 & 18.23 \\
\hline $\begin{array}{l}\text { Fo } \\
\text { males } \\
\text { (s.d) }\end{array}$ & $\begin{array}{l}104.62 \\
(2.64)\end{array}$ & $\begin{array}{l}2403 \\
(099)\end{array}$ & $\begin{array}{l}.0451 \\
(.03)\end{array}$ & $\begin{array}{l}-00037 \\
(0001)\end{array}$ & $\begin{array}{l}-00003 \\
(00001)\end{array}$ & $\begin{array}{l}-.00003 \\
(.00003)\end{array}$ & .0002 & 24 & 1206 \\
\hline $\begin{array}{l}\text { Pop } \\
\text { (s.d.) }\end{array}$ & $\begin{array}{l}11425 \\
(3.17)\end{array}$ & $\begin{array}{l}4990 \\
(11)\end{array}$ & $\begin{array}{l}.0255 \\
(04)\end{array}$ & $\begin{array}{l}.0000 \\
(0012)\end{array}$ & $\begin{array}{l}0,0002 \\
(0001)\end{array}$ & $\begin{array}{c}.0005 \\
(0000)\end{array}$ & .0001 & .17 & 20.47 \\
\hline
\end{tabular}

The ANOVA results indicate that the isokinetic torque capability responded significantly to changes in position, velocity, direction, and gender (Table 5). Furthermore, while the interaction effects of the velocity by angle are significant for the two joints, the remaining two-way interaction effects (position by direction, position by gender, velocity by direction, velocity by gender, and gender by direction) are significant for only some of the joints (Table 5). These results confirm the necessity of the surface representation of joint dynamic torque capability as a function of both the angular position and velocity since the interaction of these two main effects is significant. The Tukey posthoc tests for the velocity effect revealed that both the flexion and extension torque capabilities were signifi- cantly greater $(\mathrm{p}<.05)$ at $10,50,100$ degrees/sec as compared to 150,200 , and 250 degrees/sec for the knee and hip joints. In terms of the effect of position, the flexion and extension torque capabilities for the knee joint were found to be significantly greater at 20 , 40 , and 60 degrees of knee flexion as compared to 0 and 80 degrees. An example of the three-dimensional surface responses resulting from the torque capability regressions is shown in Figure 2 for the knee joint.

\section{DISCUSSION}

Due to the scarcity of dynamic joint torque capability normative data in literature, researchers have of- 
Table 2. Regression summary for the knee extension torque capability for 20 subjects ( $N=m 1-m 10$ : males, f11-20: females), and for the male, female and whole population $B_{0}-B_{5}$ : regression model coefficients, $R_{a}{ }^{2}$ : adjusted $R^{2}, P$ : $P$ value, $S E$ : standard error of regression $(\mathrm{Nm})$.

\begin{tabular}{|c|c|c|c|c|c|c|c|c|c|}
\hline Sub & $\mathbf{B}_{0}$ & $B_{1}$ & $B_{2}$ & $B_{3}$ & $\mathbf{B}_{4}$ & $B_{5}$ & $\mathbf{P}$ & $\mathbf{R}^{2}$ & SE \\
\hline $\mathbf{m 1}$ & 212.77 & 4.38 & .1507 & -.0053 & -.0023 & .0032 & .0001 & .66 & 14.76 \\
\hline$m_{2}$ & 181.26 & 2.72 & -.1977 & -.0400 & -.0001 & .0037 & .0008 & .75 & 17.03 \\
\hline $\mathrm{m} 3$ & 289.82 & 6.46 & -1.0146 & -.0899 & .0011 & .0043 & .00001 & .77 & 21.45 \\
\hline $\mathrm{mA}$ & 166.54 & .2387 & -.1070 & -.0032 & .0003 & -.0011 & .0001 & .66 & 6.49 \\
\hline $\mathrm{m5}$ & 232.27 & 2.5804 & .2285 & -.0379 & -.0008 & -.0036 & .0007 & .57 & 32.04 \\
\hline$m 6$ & 177.82 & 1.7266 & -.6834 & -.0205 & .0015 & -.0003 & .0002 & .72 & 18.41 \\
\hline$m 7$ & 258.54 & 1.3622 & .3812 & .0270 & -.0011 & .0050 & .0000 & .70 & 30.23 \\
\hline$m 8$ & 189.48 & 1.2388 & .3828 & -.0100 & -.0014 & -.0031 & .04082 & .23 & 23.51 \\
\hline $\mathrm{mg}$ & 155.95 & 3.41 & -.4310 & -.0407 & .0009 & .0023 & .00001 & .67 & 25.93 \\
\hline $\mathrm{m} 10$ & 180.30 & 3.0654 & -.0944 & -.0387 & .0006 & .0002 & .00871 & .74 & 4.051 \\
\hline $\begin{array}{l}\text { mean } \\
\text { (s.d.) }\end{array}$ & & & & & & & & $\begin{array}{c}.65 \\
(.15)\end{array}$ & $\begin{array}{c}19.3 \\
(8.78)\end{array}$ \\
\hline n1 & 107.48 & 1.2064 & .1343 & -.0086 & -.0007 & -.0004 & .00001 & .77 & 8.51 \\
\hline 12 & 113.94 & .0105 & .0548 & .0011 & -.0001 & .0005 & .0095 & .66 & 7.23 \\
\hline$f 13$ & 140.32 & .1097 & -.0534 &. .0044 & -.0002 & .0013 & .00046 & .49 & 6.98 \\
\hline 114 & 120.62 & .5260 & .0225 & -.0064 & .0001 & -.0010 & .0039 & .39 & 6.69 \\
\hline 115 & 149.70 & -.5627 & .0295 & .0046 & .0002 & .0008 & .0196 & .25 & 9.122 \\
\hline 116 & 147.84 & -.1615 & .0489 & .0006 & .0005 & -.0005 & .0000 & .80 & 5.36 \\
\hline$n 17$ & 157.56 & -.0562 & .0619 & -.0011 & -.0004 & .0009 & .00023 & .77 & 6.937 \\
\hline 118 & 116.60 & .3901 & .0847 & -.0051 & -.0004 & -.0001 & .0013 & .58 & 7.72 \\
\hline $\mathrm{ng}$ & 135.82 & -.0030 & .0110 & -.0008 & -.0002 & -.0010 & .0104 & .33 & 10.36 \\
\hline 120 & 136.03 & -.0064 & .1140 & .0005 & -.0005 & -.0011 & .0021 & .51 & 7.23 \\
\hline $\begin{array}{l}\text { mean } \\
\text { (s.d.) }\end{array}$ & & & & & & & & $\begin{array}{r}.54 \\
(20)\end{array}$ & $\begin{array}{r}7.92 \\
(1.55) \\
\end{array}$ \\
\hline (aded) & $\begin{array}{l}20230 \\
(12.41)\end{array}$ & $\begin{array}{r}329 \\
(44)\end{array}$ & $\begin{array}{l}-0184 \\
(10)\end{array}$ & $\begin{array}{r}-0430 \\
(0399) \\
\end{array}$ & $\begin{array}{l}0000 \\
(0000)\end{array}$ & $\begin{array}{l}-0003 \\
\text { conts }\end{array}$ & 0001 & 27 & 56.63 \\
\hline $\begin{array}{l}\text { Fo } \\
\text { males } \\
\text { (e.d) }\end{array}$ & $\begin{array}{l}13243 \\
\text { (2.29) }\end{array}$ & $\begin{array}{l}1434 \\
(18)\end{array}$ & $\begin{array}{c}0510 \\
(09)\end{array}$ & $\begin{array}{l}-00011 \\
(0013)\end{array}$ & $\begin{array}{l}.0003 \\
100094\end{array}$ & $\frac{-0000}{(0000)}$ & 0087 & .14 & 15.01 \\
\hline $\begin{array}{l}\text { Pop } \\
(0,0)\end{array}$ & $\begin{array}{c}167.36 \\
9.12\end{array}$ & $\begin{array}{l}17191 \\
(33)\end{array}$ & $\begin{array}{l}.0168 \\
(12)\end{array}$ & $\begin{array}{l}-00025 \\
(00036)\end{array}$ & $\begin{array}{l}0,0005 \\
(00004\end{array}$ & $\begin{array}{l}2,0005 \\
(0010)\end{array}$ & .0001 & 18 & 18.94 \\
\hline
\end{tabular}

ten relied on static (isometric) torque capability databases for the evaluation of dynamic MMH tasks. Gagnon and Smyth [24] used the static regressions reported by Chaffin and Andersson [29] for calculating the muscular utilization ratio (defined as the ratio of the maximum dynamic moment obtained at the joint during the motion to the maximal joint torque capability). They cite this as one of the limitations in their studies since dynamic joint moments were compared to maximal moments obtained isometrically. Similarly, Hsiang and Ayoub [25] used the same regressions (reported by Chaffin and Andersson [29]) as part of their objective function in a study simulating manual multilink coordinated lifting, a highly dynamic activity. The extensive use of static regressions is most likely due to the wide availability of reliable sources of such data representation (mainly from the University of Michigan $[3,30,31]$, and the relative success of the corresponding biomechanical models in identifying high risk jobs during maximal static and quasi-static exertions [29].

The objective of this study was to provide a normative database of 3-D dynamic surface responses of joint flexion and extension torque capability for the lower extremity knee and hip joints to fill the current void in literature. The results show that for both joints studies, torque capability was significantly influenced by dynamic parameters such as the angular velocity, and that the interaction between angular position and velocity is highly significant (Table 5). This confirms 
Table 3. Regression summary for the hip flexion torque capability for 20 subjects ( $N=m 1-m 10$ : males, f11-f0: females), and for the male, female and whole population, $B_{0}-B_{5}$ : regression model coefficients, $R_{a}{ }^{2}$ : adjusted $R^{2}, P: P$ value, $\mathrm{SE}$ : standard error of regression $(\mathrm{Nm})$.

\begin{tabular}{|c|c|c|c|c|c|c|c|c|c|}
\hline Sub & $\mathbf{B}_{\mathbf{0}}$ & $\mathbf{B}_{1}$ & $\mathbf{B}_{2}$ & $\mathbf{B}_{3}$ & $\mathbf{B}_{4}$ & $\mathbf{B}_{5}$ & $\mathbf{P}$ & $\mathbf{R}_{\mathbf{1}}{ }^{2}$ & SE \\
\hline $\mathrm{m} 1$ & 86.71 & 1.3873 & .0951 & -.0188 & -.0006 & -.0016 & .0000 & .72 & 7.20 \\
\hline $\mathrm{m} 2$ & 93.80 & .5377 & -.1316 & -.0092 & .0002 & .0006 & .0021 & .42 & 6.46 \\
\hline $\mathrm{m3}$ & 92.36 & .8383 & .0297 & -.0137 & -.0004 & -.0003 & .0001 & .75 & 5.33 \\
\hline $\mathrm{m4}$ & 86.30 & .4947 & -.0003 & -.0061 & .0002 & -.0018 & .0003 & .51 & 5.53 \\
\hline $\mathrm{m5}$ & 82.61 & .5354 & .1176 & -.0094 & -.0005 & -.0006 & .0053 & .37 & 7.22 \\
\hline m6 & 88.03 & .3145 & -.0569 & -.0033 & .0002 & -.0004 & .0094 & .65 & 4.63 \\
\hline $\mathrm{m7}$ & 102.63 & 1.3674 & .0723 & -.0199 & -.0004 & -.0006 & .0001 & .64 & 7.11 \\
\hline m8 & 86.96 & 1.2826 & .02477 & -.0137 & .0004 & -.0014 & .0006 & .58 & 6.81 \\
\hline $\mathrm{m} 9$ & 90.64 & 1.2486 & .1540 & -.0191 & -.0007 & -.0004 & .0007 & .57 & 7.12 \\
\hline $\mathrm{m10}$ & 102.97 & .8175 & -.0095 & -.0133 & -.0001 & .0003 & .0009 & .47 & 5.86 \\
\hline $\begin{array}{c}\text { mean } \\
\text { (s.d.) }\end{array}$ & & & & & & & & $\begin{array}{c}.57 \\
(.12) \\
\end{array}$ & $\begin{array}{c}6.33 \\
(0.88) \\
\end{array}$ \\
\hline f11 & 65.95 & 1.1352 & .1870 & -.0157 & -.0008 & -.0010 & .0000 & .80 & 4.40 \\
\hline $\mathrm{n2}$ & 84.78 & 1.0946 & .1214 & -.0175 & -.0007 & -.0003 & .0001 & .79 & 4.65 \\
\hline 113 & 62.08 & .8026 & .0300 & -.0083 & -.0003 & -.0010 & .0000 & .79 & 4.61 \\
\hline f14 & 72.65 & .5209 & .0076 & -.0107 & -.0003 & .0007 & .0001 & .56 & 4.71 \\
\hline f15 & 85.07 & .5029 & -.0706 & -.0103 & -.0001 & .0007 & .0001 & .69 & 5.32 \\
\hline f16 & 93.53 & .5615 & -.0829 & -.0110 & -.0001 & .0008 & .0001 & .68 & 5.72 \\
\hline f17 & 77.33 & .9088 & .1432 & -.0133 & -.0008 & -.0008 & .0113 & .33 & 11.53 \\
\hline $\mathbf{f 1 8}$ & 66.56 & 1.2875 & -.1030 & -.0128 & .0002 & -.0010 & .0000 & .81 & 6.11 \\
\hline f19 & 62.44 & .67853 & .0329 & -.0062 & -.0002 & -.0013 & .0007 & .48 & 6.02 \\
\hline 20 & 70.24 & .6338 & .1504 & -.0047 & -.0007 & -.0014 & .0001 & .66 & 6.10 \\
\hline $\begin{array}{l}\text { mean } \\
\text { (s.d.) }\end{array}$ & & & & & & & & $\begin{array}{c}.66 \\
(.15)\end{array}$ & $\begin{array}{c}5.92 \\
(1.98) \\
\end{array}$ \\
\hline $\begin{array}{l}\text { Males } \\
\text { (s.d.) }\end{array}$ & $\begin{array}{l}91.30 \\
(2.63) \\
\end{array}$ & $\begin{array}{l}.8824 \\
(.13)\end{array}$ & $\begin{array}{l}.0295 \\
(.04)\end{array}$ & $\begin{array}{l}-.0126 \\
(.0018)\end{array}$ & $\begin{array}{l}-.0002 \\
(.0001)\end{array}$ & $\begin{array}{r}.0006 \\
(.0004)\end{array}$ & .0001 & .22 & 12.01 \\
\hline $\begin{array}{l}\text { Fe } \\
\text { males } \\
\text { (sd.) }\end{array}$ & $\begin{array}{l}74.06 \\
(2.27)\end{array}$ & $\begin{array}{l}.8126 \\
(.11)\end{array}$ & $\begin{array}{l}.0416 \\
(.03)\end{array}$ & $\begin{array}{l}-.0111 \\
(.0016)\end{array}$ & $\begin{array}{l}-.0004 \\
(.0001)\end{array}$ & $\begin{array}{l}. .0005 \\
(.003)\end{array}$ & .0000 & 35 & 10.37 \\
\hline $\begin{array}{l}\text { Pop } \\
\text { (s.d.) }\end{array}$ & $\begin{array}{l}82.68 \\
(2.25)\end{array}$ & $\begin{array}{c}.8475 \\
(.1074)\end{array}$ & $\begin{array}{r}.0356 \\
(.0296)\end{array}$ & $\begin{array}{l}-.0118 \\
(.0016)\end{array}$ & $\begin{array}{l}-.00003 \\
(.0001)\end{array}$ & $\begin{array}{l}.0005 \\
(.0003)\end{array}$ & .0001 & .28 & 14.53 \\
\hline
\end{tabular}

earlier results $[4,5,32,33]$ and extends it over a wider range of the dynamic variables (Table 6). The direct comparison of this data to existing literature is difficult due to relatively a complete lack of available studies that investigated the same range of dynamic variables, and almost the lack of studies that reported the results in the form of 3-D surface responses. Nonctheless, comparison with other isokinetic studies reveals that the isokinctic peak torques compared well with those of past literature (Table 6). Differences may be attributed to the use of different isokinetic dynamometers, testing protocols, population demographics, and activity level.

In agreement with findings of other researchers, the results demonstrated a general trend of decreasing joint torque magnitude with increasing angular velocity $[3,4,13,33]$. However, it was observed that the isokinetic muscular torque tends to rise less steeply as the speed approaches zero as compared to the classic hyperbolic force-velocity curve obtained by Hill [18]. Other studies have shown a similar trend of "flattening" or decline of force production at low isokinetic speeds $[4,12]$. Possible mechanisms postulated behind this deviation from the classic Hill curve include fatigue effects (usually more pronounced at lower velocities), neural inhibition of the force generated in the intact muscle as the tension rises, and increases of antagonistic force to prevent joint damage [4,12-15].

The angular position at which dynamic peak torque occurs is important in the ergonomic assess- 
Table 4. Regression summary for the hip extension torque capability for 20 subjects (N=m1-m10: males, f11-f20: females), and for the male, female and whole population, $B_{0}-B_{5}$ : regression model coefficients, $R_{a}{ }^{2}$ : adjusted $R^{2}, P$ : $P$ value, $S E$ : standard error of regression $(\mathbf{N m})$.

\begin{tabular}{|c|c|c|c|c|c|c|c|c|c|}
\hline Sub & $\mathbf{B}_{\mathbf{0}}$ & $\mathbf{B}_{1}$ & $\mathbf{B}_{2}$ & $\mathbf{B}_{\mathbf{3}}$ & $\mathbf{B}_{4}$ & $\mathbf{B}_{5}$ & $\mathbf{P}$ & $\mathbf{R}_{\mathbf{q}}{ }^{2}$ & $\mathbf{S E}$ \\
\hline m1 & 108.19 & .6472 & .1620 & -.0073 & -.0010 & -.0002 & .0001 & .70 & 6.68 \\
\hline $\mathrm{m} 2$ & 106.75 & .6873 & .1715 & -.0098 & -.0008 & -.0003 & .0007 & .58 & 5.50 \\
\hline $\mathbf{m} 3$ & 115.51 & 1.0894 & .0686 & -.0162 & -.0002 & -.0014 & .0152 & .31 & 9.19 \\
\hline $\mathrm{m4}$ & 91.23 & 3.12 & .1079 & -.0480 & -.0009 & .0008 & .0001 & .66 & 14.91 \\
\hline $\mathrm{m5}$ & 97.75 & .8060 & .0914 & -.0113 & -.0003 & -.0008 & .0003 & .51 & 4.38 \\
\hline m6 & 120.34 & .6997 & .0225 & -.0114 & .0001 & -.0013 & .0039 & .39 & 6.68 \\
\hline $\mathrm{m} 7$ & 101.10 & 1.8052 & .0563 & -.0232 & -.0003 & -.0002 & .0001 & .73 & 7.38 \\
\hline $\mathrm{m8}$ & 114.54 & 2.1285 & -.0837 & -.0234 & .0003 & -.0026 & .0003 & .61 & 11.76 \\
\hline m9 & 132.43 & 2.4043 & -.5552 & -.0331 & .0015 & .0001 & .0001 & .89 & 3.69 \\
\hline m10 & 126.33 & 1.64 & -.0050 & -.0263 & -.0004 & .0005 & .0001 & .82 & 6.03 \\
\hline $\begin{array}{c}\text { mean } \\
(\text { s.d. })\end{array}$ & & & & & & & & $\begin{array}{c}.62 \\
(.17) \\
\end{array}$ & $\begin{array}{c}7.62 \\
(3.28) \\
\end{array}$ \\
\hline f11 & 93.75 & .9543 & .1138 & -.0119 & -.0005 & -.0008 & .0007 & .48 & 6.63 \\
\hline $\mathbf{f 1 2}$ & 104.53 & .8007 & .1005 & -.0113 & -.0005 & -.0002 & .0001 & .56 & 5.00 \\
\hline $\mathrm{f13}$ & 105.55 & .7418 & -.0305 & -.0139 & -.0002 & .0007 & .0001 & .66 & 4.85 \\
\hline 114 & 105.58 & .1961 & .0138 & -.0046 & -.0001 & .0007 & .0311 & .43 & 4.85 \\
\hline f15 & 118.13 & .3186 & -.0815 & -.0099 & -.0001 & .0020 & .0022 & .42 & 6.38 \\
\hline $\mathrm{f16}$ & 95.13 & 1.46 & .0636 & -.0247 & -.0003 & -.0005 & .0001 & .56 & 8.54 \\
\hline f17 & 90.37 & 1.2942 & -.0709 & -.0172 & .0003 & -.0006 & .0050 & .38 & 9.25 \\
\hline $\mathrm{f18}$ & 84.09 & 1.2692 & .2001 & -.0168 & -.0007 & -.0001 & .0001 & .66 & 6.44 \\
\hline f19 & 95.55 & 1.2018 & .0123 & -.0180 & -.0004 & -.0008 & .0001 & .69 & 8.37 \\
\hline 20 & 111.41 & .9166 & -.1248 & -.0137 & .0001 & -.0001 & .0001 & .80 & 5.40 \\
\hline $\begin{array}{c}\text { mean } \\
(\text { s.d.) }\end{array}$ & & & & & & & & $\begin{array}{c}.56 \\
(.13)\end{array}$ & $\begin{array}{r}6.57 \\
(1.55)\end{array}$ \\
\hline $\begin{array}{l}\text { Males } \\
\text { (s.d.) }\end{array}$ & $\begin{array}{c}111.42 \\
(3.06)\end{array}$ & $\begin{array}{c}1.5032 \\
(.15) \\
\end{array}$ & $\begin{array}{l}.0036 \\
(.04) \\
\end{array}$ & $\begin{array}{r}-.0210 \\
(.002) \\
\end{array}$ & $\begin{array}{l}-.0002 \\
(.0001)\end{array}$ & $\begin{array}{l}-.0005 \\
\text { (0005) }\end{array}$ & .0000 & 34 & 13.97 \\
\hline $\begin{array}{l}\text { Fe- } \\
\text { males } \\
\text { (sd.) }\end{array}$ & $\begin{array}{c}100.41 \\
(2.05)\end{array}$ & $\begin{array}{l}.9158 \\
(.10)\end{array}$ & $\begin{array}{l}.0197 \\
(.03)\end{array}$ & $\begin{array}{l}.0142 \\
(.0014)\end{array}$ & $\begin{array}{l}-.0002 \\
(.0001)\end{array}$ & $\begin{array}{l}.0001 \\
(.0001)\end{array}$ & .0001 & $\mathbf{3 3}$ & 9.35 \\
\hline $\begin{array}{l}\text { Pop } \\
\text { (s.d.) }\end{array}$ & $\begin{array}{c}105.91 \\
(2.26)\end{array}$ & $\begin{array}{l}1.290 \\
(.11)\end{array}$ & $\begin{array}{l}.0116 \\
(.03)\end{array}$ & $\begin{array}{l}-.0176 \\
(.0015)\end{array}$ & $\begin{array}{l}-.00012 \\
(.0001)\end{array}$ & $\begin{array}{l}-.0003 \\
(\mathbf{O O M B})\end{array}$ & .0001 & .25 & 1457 \\
\hline
\end{tabular}

ment of functional muscular torque in order to design tasks such that one opcrates in the most optimal range of motion $[4,13]$. The results of this study showed that the peak torque values occurred in a relatively narrow range of motion (Table 7). Furthermore, a shift in the position of peak torque of the knee joint was observed in response to higher angular velocity (i.e. the peak torque values occurred later in the range of motion at higher velocities) (Table 8). Other studies have described similar results for knee joint extension $[4,33]$. Such changes in peak torque position accompanying speed variation have been attributed to longer acceleration period at faster speed, as the limb is trying to reach the preset speed of the dynamometer. Conse- quently, as the speed increases, the maximum torque tends to occur later in joint the range of motion and not in the optimal joint position (the joint position defined by the muscle length and joint leverage for optimal performance) $[13,29]$.

Female joint torque capability has been reported to be 56 to 72 percent of the males $[3,13]$. Consistently, the results of this study showed on average female joint torque capability to be $54.7 \%$ for the hip joint and $63.6 \%$, for the knee.

It should be noted that the model's overall significance was considered rather than testing for the significance of individual coefficients in order to avoid any erroneous conclusions due to potential existing 
Table 5. The results of ANOVA on isokinetic torque capability of the knee and hip joints for the main effects of angle, velocity, direction, gender and the two-way significant interactions $\left(^{* *}: P<0.001, *\right.$ : $P<\quad$ 0.05, NS: Not Significant)

\begin{tabular}{|c|c|c|}
\hline Source & \multicolumn{2}{|c|}{ P Value } \\
\hline Angle & Knee & Hip \\
\hline Velocity & $.0001^{\circ}$ & $.0121^{\circ}$ \\
\hline Direction & $.0423^{\circ}$ & $.0001^{\circ}$ \\
\hline Gender & $.0001^{\circ}$ & $.0025^{\circ}$ \\
\hline Ang*Vel & $.0002^{* *}$ & $.0081^{*}$ \\
\hline Ang*Dir & $.0010^{* *}$ & $.0057^{* *}$ \\
\hline Ang*Gen & .0621 & $.0136^{*}$ \\
\hline Vel*Dir $^{*}$ NS & NS \\
\hline Vel*Gen $^{*}$ Gen & NS \\
\hline Gen*Dir & .0020 & NS \\
\hline
\end{tabular}

are strong dependencies among the regressor variables, which may affect the precision of the estimated regression coefficients [38]. The variance inflation caused by multicollinearity may lead to non-significant results based on individual $t$-ratio testing of the significance of each regressor (i.e. whether $B_{i}$ is significantly greater than zero). Conversely, prediction of the model's mean response is unaffected by collinearity [34] Hence no attempt has been made to test the significance of each coefficient as the adequacy of the overall model has been investigated in terms of significant level of $F$-ratio, adjusted $\mathrm{R}^{2}$ and $\mathrm{SE}$.

The robustness of the regression model can be demonstrated by examining Table 9. The results shown in that table reflect the overall robustness in performance as indicated by the consistent adjusted $R^{2}$ values of the models developed from trial one to estimate the torque capability of trial 2 (Table 9). In general, more stable are obtained hy pooling and averaging the separate trials due to reduction of random noise or experimental error. While the results of this study confirm the appropriateness of developing the regres- sion models using the average of the two trials, further work is needed to explore this issue by investigating more examples.

It is important to caution that extrapolation of the present results should be avoided. In general, extrapolating any normative torque capability or range of motion database to a different population such as older workers or disabled individuals or over a different set of independent variables (i.e. angles and velocities) may lead to erroneous results [28].

\section{Limitations}

The use of isokinetic devices to obtain functional torque capability measurements has inherent limitations that need to be addressed $[4,13,35]$ Several studics have shown differences between measurements reported by isokinetic dynamometers and the calculated intersegmental joint moments [22,36]. Differences have been attributed to gravitational effects, inertial effects, and system configuration effects (alignment, non-rigidity, and duration of constant velocity). Efforts were made in this study to minimize the aforementioned errors whenever possible by correcting for gravity, climinating the non-isokinetic portion of the exertions, as well as minimizing the error introduced by misalignment via proper stabilization of the tested joints. The uncontrolled sources of error contributed to the residual term in the regression model.

Another issue of importance is the effect of hiarticular muscles. Since muscles often span more than one joint, the orientation (joint angle) at adjacent joints should be considered in the prediction of joint torque capability $[13,20]$ Such considerations have been implemented by Hoy et al. [20] for static conditions. In their musculoskeletal model of the lower extremity, they found that for biarticular actuators with short muscle fibers relative to the moment arm, the peak moment about one of the spanned joints is very sensitive to the orientation of the other spanned joints. For example, the relative contributions of the Soleus and Gastrocnemius muscles about the ankle joint depended on knee angle [20]. In this study, the torque at the hip joint depends on the knee position since the biarticular

Table 6. The results of the regression models for subject $\mathrm{m} 3$ using the torque capability data from trial 1 , averaged data from trial 1 and 2 , and using the model resulting from trial 1 to fit the torque capability data of trial 2 .

\begin{tabular}{|c|l|c|c|}
\hline Joint & \multicolumn{1}{|c|}{ Trial } & Adjusted R & Standard Error (Nm) \\
\hline Knee Flexion & Trial 1 & .58 & 15.23 \\
& Average Trial (1\&2) & .75 & 8.94 \\
& Model from Trial 1 for & .60 & 10.62 \\
& prediction of Trial 2 & & 4.73 \\
\hline Hip Flexion & Trial 1 & .77 & 4.33 \\
& Average Trial (1\&2) & .78 & 5.85 \\
& Model from Trial 1 for & .75 & \\
& prediction of Trial 2 & & \\
\hline
\end{tabular}


Table 7. Torque capability normative values of mean flexion/extension peak torque (Nm) for the ankle (dorsi/plantar), knee, and hip.joints as compared to values in literature.

\begin{tabular}{|c|c|c|c|c|c|c|c|}
\hline Joint & Study & $\begin{array}{c}\begin{array}{c}\text { Vel } \\
\text { (deg/sec) }\end{array} \\
\end{array}$ & Age & Sex & Device & $\begin{array}{c}\text { Flexion (Nm) } \\
\text { Mean (s.d.) } \\
\end{array}$ & $\begin{array}{c}\text { Extension (Nm) } \\
\text { Mean (s.d.) }\end{array}$ \\
\hline \multicolumn{8}{|l|}{ Knee } \\
\hline & Thorstensson el al. (1976) & 15 & $17-37$ & $M$ & Cybex 11 & N/A & $184.4(6.9)$ \\
\hline & & 30 & & & & $N / A$ & $180.4(6.9)$ \\
\hline & & 60 & & & & N/A & $171.6(5.9)$ \\
\hline & & 90 & & & & N/A & $161.8(5.9)$ \\
\hline & & 180 & & & & $\mathrm{~N} / \mathrm{A}$ & $119.6(3.9)$ \\
\hline & Wickiewicz et al. (1984) & 12 & $20-38$ & $\mathrm{M} / \mathrm{F}$ & Cybex II & $114(25)$ & $128(46)$ \\
\hline & & 47.6 & & & & $116(28)$ & $147(37)$ \\
\hline & & 96.3 & & & & $103(24)$ & $125(35)$ \\
\hline & & 143.9 & & & & $84(24)$ & $100(31)$ \\
\hline & & 192 & & & & $69(23)$ & $83(29)$ \\
\hline & & 240.2 & & & & $54(20)$ & $67(28)$ \\
\hline & Alexander (1990) & 30 & $22(6.6)$ & $\mathrm{M} / \mathrm{F}$ & $\begin{array}{c}\mathrm{KI}{ }^{61 \mathrm{~N}}- \\
\mathrm{COM}\end{array}$ & $148(36)$ & $232(62)$ \\
\hline & & 230 & & & & $145(37)$ & $179(66)$ \\
\hline & Seger \&Thorstensson (1994) & 45 & $22-35$ & $M$ & Spark & N/A & $189(13)$ \\
\hline & & 90 & & & & $\mathrm{~N} / \mathrm{A}$ & $178(9)$ \\
\hline & & 180 & & & & $\mathrm{~N} / \mathrm{A}$ & $142(8)$ \\
\hline & & & & & & & \\
\hline & Present Study & 10 & $26(3.8)$ & $\mathbf{M}$ & KIN-COM & $131.51(6.8)$ & $227.1(11.6)$ \\
\hline & & 50 & & & & $118.5(11.2)$ & $216.8(10.3)$ \\
\hline & & 100 & & & & $94.3(7.4)$ & $176.4(8.4)$ \\
\hline & & 150 & & & & $80.7(9.5)$ & $161.5(9.0)$ \\
\hline & & 200 & & & & $73.4(10.6)$ & $155.4(15.3)$ \\
\hline & & 250 & & & & $70.8(5.4)$ & $148.8(16.7)$ \\
\hline & & 10 & $24(2.4)$ & $F$ & KIN-COM & $87.3(3.3)$ & $122.9(7.4)$ \\
\hline & & 50 & & & & $83.7(6.5)$ & $117.6(5.4)$ \\
\hline & & 100 & & & & $77.4(5.3)$ & $100.1(9.2)$ \\
\hline & & 150 & & & & $702(6)$ & $915(8)$ \\
\hline & & 200 & & & & $61.9(4.1)$ & $73.2(5.1)$ \\
\hline & & 250 & & & & $58.1(3.7)$ & $70.4(4.6)$ \\
\hline \multirow[t]{23}{*}{ Hip } & Study & Vel & Age & Sex & Device & Flexion (Nm) & Extension (Nm) \\
\hline & Cahalan et al. (1988) & 30 & $20-40$ & $M$ & Cybex II & $152(50)$ & $177(42)$ \\
\hline & & 90 & & & & $126(50)$ & $163(49)$ \\
\hline & & 150 & & & & $102(47)$ & $142(49)$ \\
\hline & & 210 & & & & $91(50)$ & $125(52)$ \\
\hline & Nicholas et al. (1989) & 30 & $20-30$ & $\mathrm{M} / \mathrm{F}$ & KIN-COM & $102(21)$ & $120(25.3)$ \\
\hline & Alexander $(1990)$ & 30 & $22(6.6)$ & $\mathrm{M} / \mathrm{F}$ & KIN-COM & $210(73)$ & $297(93)$ \\
\hline & & 180 & & & & $180(66)$ & $175(78)$ \\
\hline & Ford et al (1994) & 60 & $25(4.9)$ & $\mathrm{M} / \mathrm{F}$ & $\begin{array}{l}\text { Biodex B- } \\
2000\end{array}$ & $197.4(62.1)$ & $101.5(37.5)$ \\
\hline & & 300 & & & & $108.3(38.1)$ & $93.5(34.3)$ \\
\hline & & & & & & & \\
\hline & Present Study & 10 & $26(3.8)$ & $\mathbf{M}$ & $\mathrm{KIN}-\mathrm{COM}$ & $148.45(33.25)$ & $182.39(45.92)$ \\
\hline & & 50 & & & & $135.22(21.56)$ & $173.47(44.43)$ \\
\hline & & 100 & & & & $121.12(34.65)$ & $151.88(30.41)$ \\
\hline & & 150 & & & & $104.28(24.8)$ & $138.35(25.28)$ \\
\hline & & 200 & & & & $93.72(22.43)$ & $122.96(31.77)$ \\
\hline & & 250 & & & & $86.25(16.95)$ & $97.05(33.69)$ \\
\hline & & 10 & $24(2.4)$ & $\mathbf{F}$ & KIN-COM & $95.67(43.35)$ & $124.36(29.34)$ \\
\hline & & 50 & & & & $82.46(30.24)$ & $103.65(27.46)$ \\
\hline & & 100 & & & & $74.08(22.87)$ & $92.52(30.98)$ \\
\hline & & 150 & & & & $63.45(29.35)$ & $83.74(31.5)$ \\
\hline & & 200 & & & & $55.36(19.24)$ & $71.04(19.08)$ \\
\hline & & 250 & & & & $40.52(20.64)$ & $63.77(21.22)$ \\
\hline
\end{tabular}


Table 8. Mean (s.d.) of peak torque angular position for the ankle, knee, and hip joints

\begin{tabular}{|c|c|c|}
\hline Joint & Direction of exertion & $\begin{array}{c}\text { Angular Position } \\
\text { (deg) }\end{array}$ \\
\hline Knee & Flexion & $51.7(3.5)$ \\
\hline Hip & Extension & $51.5(2.9)$ \\
\hline & Flexion & $17.5(6.7)$ \\
\hline & Extension & $6.2(5.8)$ \\
\hline
\end{tabular}

Table 9. Mean (s.d.) knee peak torque angular position with different angular velocities

\begin{tabular}{|c|c|c|}
\hline $\begin{array}{c}\text { Angular Ve- } \\
\text { locity } \\
\text { (deg/sec) }\end{array}$ & $\begin{array}{c}\text { Knee } \\
\text { Flexion }\end{array}$ & $\begin{array}{c}\text { Knee Exten- } \\
\text { sion }\end{array}$ \\
\hline 10 & $46(1.2)$ & $58(1.9)$ \\
\hline 50 & $48(2.4)$ & $56(5.8)$ \\
\hline 100 & $50(3.3)$ & $54(5.2)$ \\
\hline 150 & $55(4.8)$ & $53(4.7)$ \\
\hline 200 & $56(3.2)$ & $46(1.9)$ \\
\hline 250 & $55(2.7)$ & $42(1.6)$ \\
\hline
\end{tabular}

biceps femoris (knee flexor, hip extensor) spans both joints. The isokinetic apparatus used here made it somewhat difficult to isolate the hip joint in particular. While the regression model includes the uncontrolled sources of error as part of the residual term, it should be kept in mind that better postural stabilization that isolates the hip joint might be achieved via a different testing configuration. Furthermore, since the present torque capability prediction model is specific to the tested configurations (Figure $1(\mathrm{a}, \mathrm{b})$ ), a more extensive experimental study could be designed to incorporate the effect of adjacent joint postures on the dynamic torque capability of joints with major biarticular muscles. Unfortunately, such complex experimental design incorporating the various combinations of angular positions and velocities of adjacent joints poses tremendous difficulty both in terms of data collection time and the undesirable effects of fatigue. To that end, muscle-driven models [21] provide an attractive alternative specially for joints dominated by biarticular muscles. Furthermore, such models may be used to explore the adequacy of experimentally driven response surfaces based on various muscle and joint combinations.

Scholz et al. [37] and Sparto et al. [10] have quantified stable coordinated phases between joint trajectories during lifting. This coordinative structure may aid in reducing the degrees of freedom in performing the task. Additional studies need to consider covariance of joint trajectories during goal oriented tasks such as lifting. Such consideration may also reduce the dimensionality of sampled functional space in optimal experimental designs [38].

When using polynomial regression models, it is usually recommended to use the lowest-degree model consistent with the data (principle of parsimony) [38]. In this study, due to degree of freedom considerations (number of data points included in modeling of the torque capability for each subject per joint $=30$ ), the adequacy of the second-order polynomial as measured by the adjusted coefficients of multiple determination $\left(R^{2}\right)$ and standard error of regression indicated a reasonable model for most of the subjects (Tables 1-4). While the preliminary results of the robustness test are satisfactory, further confirmation is necessary by investigating additional subjects.

Lastly, considering that MMH tasks usually require a coordinated multi-link activity, coordinated multijoint torque capability assessment protocols may provide a better torque capability evaluation tool [9$11,29]$. Nonetheless, regardless of the torque capability testing battery used, dynamic torque capability data should be represented as a 3-D surface when possible, allowing more accurate interpretation of muscle function [14].

\section{CONCLUSION}

This study provides a normative database of 3-D dynamic surface rcsponses of joint flexion and extension torque capability for the lower extremity knee and hip joints for twenty normal males and females. Such representation may be used as a "performance capacity envelope" [1] to comprehensively characterize the individual's dynamic joint torque capability. Examples of potential applications cover a broad spectrum ranging from rehabilitation to ergonomic and biomechanical applications. Determination of the extent of disability has significant implications in terms of guiding job 
assignment, return to work, as well as prognosis during the rehabilitation processes. The need for more objective understanding and documentation of the effect of dynamic joint position and velocity on joint torque capability is further enhanced by the implementation of The Americans with Disabilities Act (ADA). The torque capability profiles developed in this study would provide a benchmark against which the performance of a disabled person can be measured, so that "reasonable accommodations" could be designed, rehabilitation strategies could be planned, and assistive devices could be developed or evaluated.

Ergonomic applications include combining the torque capability profiles with torque requirements from a manual material handling task, i.e. a lifting task, to compute the dynamic utilization ratio [24]. The utilization ratio provides a joint-specific unified scalar quantity representing the task demand normalized by an individual's maximum capacity [1]. It would indicate whether a subject is capable of performing the task and how much of his/her maximum capacity is "taxed" by a given physical activity. Other possible areas of application include quantitative gait studics to validate the muscle moments estimated by the various modeling approaches and computer simulations of gait and other physical activities $[23,25,26]$.

\section{REFERENCES}

1. Kondraske, G.V. (1990). Quantitative measurement and assessment of performance. CRC Rehab. Eng. (Edited by Smith R.V., and Leslie J.H.), pp.101125. Boca Raton, FL.

2. Khalaf, K.A., Parnianpour, M., and Sparto, P.J. (1997a). Modeling of functional trunk performance: Interfacing ergonomics and spine rehabilitation in response to the ADA, J. of Rehab. Res. and Develop. 34(4): 459-469.

3. Stobbe, T. (1982). The development of a practical torque capability testing program for industry, unpublished Ph.D. dissertation (Industrial Engineering), University of Michigan, Ann Arbor.

4. Osternig, L.R. (1988). Isokinetic dynamometry: implications for muscle testing and rehabilitation, Exerc. Sport Sci.Rev., 14, 45-80.

5. Alexander, M.J.L. (1990). Peak torque values for antagonist muscle groups and concentric and eccentric contraction types for elite sprinters, Arch. Phys. Med. Rehabil., 71, 334-339.

6. Ayoub, M.M., Mital, A., Bakken, G. M., Asfour, S.S., and Bethea, N.J. (1980). Development of torque capability and capacity norms for manual materials handling activities: The state of the art, Human Factors, 22, 271-283.

7. Snook, S.H. (1985). Psychophysical considerations in permissible load, Ergonomics ,28, 327-330.
8. Parnianpour, M., Hasselquist, L., Fagan, L., and Aaron, A (1993). Correlation among isometric, isokinetic, and isoinertial muscle performance during multi-joint coordinated exertions and isolated joint trunk exertion, Eur. J. Phys. Med. Rehab., 3, 114-122.

9. Sparto, P.J., Khalaf, K.A., and Parnianpour, M. (1993). The effect of load, mode, and speed of lift on the joint energetics during unconstrained lifting and lowering activities. In Advances in Bioengineering (cdited by Tarbell), pp. 467-470, ASMEBED, 26.

10.Sparto, P.J., Parnianpour, M., Reinsel, T.E., and Simon, S. (1997). The effect of fatigue on multijoint kinematics, coordination, and postural stability during a repetitive lifting test, Journal of Orthopaedic and Sports Physical Therapy, 25, 3-

11.Sparto, P.J., Parnianpour, M. and Khalaf K.A. (1995). The reliability and validity of a lift simulator and its functional equivalence with free weight lifting tasks, IEEE Trans. Rehab. Eng., 3, 155-165.

12.Perrine, J.J., and Edgerton, V.R. (1978). Muscle force-Velocity relationships under isokinetic loading, Med. Sci. Sports, 10, 159-166.

13. Cabri, J.M.H. (1991). Isokinetic torque capability aspects of human joints and muscles, Crit. Rev. Biomed. Eng., 19, 231-259.

14. Perrin, D.H. (1993). Isokinetic Exercise and Assessment (Edited by Roselund, D.) Human Kinetics Publishers, Champaign, IL.

15. Gleeson, N.P., and Mercer, T.H. (1996). The Utility of isokinetic dynamometry in the assessment of human muscle function, Sports Med., 21, 18-34.

16. Marshall, R.N., Mazur, S.M., and Taylor, N.A.S. (1990) Threedimensional surfaces for human muscle kinetics. Eur. J. Appl. Physiol, 61:263-270.

17. Osternig, L.R., Hamill, J., Sawhill, J.A., and Bates, B.T. (1983). Influence of torque and limb speed on power production in isokinetic exercise, Am. J. Phys. Med., 62, 163-171.

18. Hill, A.V. (1938). The heat of shortening and dynamic constants of muscle. Proc. Roy. Soc. b126, 53-66.

19. Winters, J.M. (1995). Concepts in neuromuscular modeling, In: Three-dimensional analysis of human movement (Edited by Allard, P., Stokes, I.A.F., and Blanchi, J-P.) pp. 257-292, Human Kinetics,Champain, IL.

20.Hoy, M.G., Zajac, F.E., and Gordon, M.E. (1990). A musculoskeletal model of the human lower extremity: the effect of muscle, tendon, and moment arm on the moment-angle relationship of musculotendon actuators at the hip, knee, and ankle, $J$. Biomechanics, 23, 157-169.

21.Delp, S.L., Loan, J.P., Hoy, M.G., Zajac, F.E., Topp, e.L., and Rosen, J.M. (1990). An interactive graphics-based model of the lower extremity to 
study orthopedic surgical procedures, IEEE Trans., 37, 757-767.

22. Winter, D.A. (1990). Biomechanics and motor control of human movement. John Wiley and Sons Inc. New York, NY. Fiber composition in human knee extensor muscles, J. Appl. Phys., 40, 12-16.

23. Khalaf, K.A., Parnianpour, M., Wade, L., and Simon, S.R. (1996). Biomechanical simulation of manual multi-link coordinated lifting. The Fifteenth Southern Biomedical Engineering Conference, 197-198, Dayton, Ohio.

24.Gagnon, M., and Smyth, G. (1991). Muscular mechanical energy expenditure as a process pf detecting potential risks in manual materials handling, $J$. Biomechanics, 24, 191-203.

25.Hsiang, S.M., and Ayoub, M.M. (1994). Development of methodology in biomechanical simulation of manual lifting. J. Industrial Ergonomics, 13, 271-288.

26 Chow, C.K., and Jacobson, D.H. (1971). Studies of human locomotion via optimal programming, Mathematical Biosciences, 10, 239-306.

27 Clinical Desk Reference (1992). KIN-COM II and III Muscle Testing and Training System Chattecx Corp., Part of Chatanooga Group Inc., Hixon, Tenn.

28. Mayhew, T.P., Rothstein, J.M., Finucane, S.D.G., and Lamb, R.L. (1994). Performance characteristics of the KIN-COM, Phys. Ther., 74, 1047-1054.

29. Chaffin, D.B., and Andersson, G.B. (1991). Occupational Biomechanics. 2nd edition. John Wilcy and Sons Inc., New York, NY.

30 Clarke, H.H. (1966). Muscle torque capability and endurance in man, Prentice-Hall, Englewood Cliffs., CA.

31. Burggraff, J.D. (1972). An isometric biomechanical model for sagittal plane leg extension, unpublished M.S. thesis, University of Michigan, Ann Arbor.

32.Cahalan, T.D., Johnson, M.S., Liu, M.D., and Chao, E.Y.S. (1989). Quantitative measurements of hip strength in different age groups, Clin. Ortho. Rel. Res., 246, 136-145.

33. Thorsrensson, A., Grimby, G., and Karlsson, J. (1976). Force-velocity relations and fiber composition in human knee extensor muscles, J. Appl. Phys., 40, 12-16.

34. Neter, J., Kutner, M.H., Nachtsheim, C.J., and Wasserman, W. (1996). Applied Linear Statistical Models. Erwin, Chicago, IL.

35.An, K-N., Kaufman, K.R., and Chao, E. Y.-S. (1995). Estimation of muscle and joint forces, In: Three-Dimensional Analysis of Human Movement (edited by Allard, P., Stokes, I.A.F., and Blanchi, J.-P.) pp.201-214, Human Kinetics, Champaign, IL.

36. Hof, A.L. (1997). Correcting for limb inertia and compliance in fast ergometers. J. Biomechanics, 30 ,
295-297.

37. Scholz, J.P. (1993). The effect of load scaling on the coordination of manual squat lifting, Hum. Move. Sci., 12, 427-459.

38. Montgomery, D.C., and Runger, G.C. (1994). Applied Statistics and Probability for Engineers. John Wiley \& Sons, New York.

\section{Appendix}

\section{Multiple Regression Model}

The order of the multiple regression model was determined a priori based on statistical analyses performed on simulated ankle and knee torque capability data. Maximum moments about the knee and ankle joints were estimated using the interactive, graphicsbased software SIMM (Software for Interactive Musculoskeletal Modcling, MusculoGraphics Inc., Evanston, IL) [21]. It was assumed that with respect to the particular movement, the agonists were contracting maximally throughout the range of motion, while the antagonists were completely silent. The sum of individual generated muscle moments was used to estimate maximal torque capability for each direction of exertion. The muscle groups used in the simulation included the ankle plantar flexors (Gastrocnemius, Soleus, Tibialis Posterior, Peroneus Brevis, Peroneus Longus, Flexor Hallucis, and Flexor Digitorum), the ankle dorsi flexors (Tibialis Anterior, Peroneus Tertius, Extensor Digitorum, and extensor Hallucis), the knee flexors (Semimembranosus and Tendinosus, Biceps Femoris (short and long heads), Sartorius, Gracilis, and Gastrocnemius), and knee extensors (Rectus Femoris, Vastii (Medialis, Lateralis, and Intermedius)). The joint moments were estimated as a function of angular position and velocity taking into account the force-length and force-velocity relationships, as well as the individual muscle parameters such as maximum isometric force, pennation angle, optimal fibre length, and tendon slack length. The angular positions and velocities used in the simulations were based on the experimental design used in this study (Figure 1). For example, the experimental procedure to evaluate the ankle joint required that the knee was extended; consequently, during the simulation of the ankle joint, care was taken to ensure that the knee was in the extended position.

Regression analyses showed that a second-order multiple regression model adequately represented the simulated torque capability data for both the ankle and knee joints as indicated by the high cocfficients of multiple determination $\left(R^{2}\right)$ and low standard errors of regression (SE). 